\title{
Open Access Journals: Knowledge and Attitudes among Cuban Health Researchers
}

\author{
Nancy Sánchez Tarragó, MSc, J. Carlos Fernández Molina, PhD
}

\begin{abstract}
A descriptive, cross-sectional study is presented whose objective was to determine the level of knowledge about and the attitudes toward open access journals among Cuban health researchers. To this end, a printed questionnaire was distributed between March and June 2007 to a group of researchers from Cuban national health institutes, who were chosen through stratified random sampling (160 researchers from 11 institutes). Variables included level of information about Open Access Movement terms and initiatives; papers published in open access journals; and reasons to publish, or not to publish, papers in such journals. Descriptive statistics, bivariate correlations, and correspondence analysis were done using the SPSS statistical software, version 10.0 for Windows. Little knowledge of open access journals and other Open Access Movement terms and initiatives, and little use of open access journals as a publication means, were observed.
\end{abstract}

Key words: Open access journals; Cuba; research institutes; Open Access Movement

\section{INTRODUCTION}

The last few decades have witnessed a worsening of the crisis in the scientific communication system, largely due to the rising prices of scientific journals beyond the means of a considerable part of the scientific community; tighter restrictions on the dissemination of scientific study results, imposed by copyright laws; and issues concerning the scientific citation system, among others.

The Open Access Movement for scientific information arose in response to this crisis. Basically, this movement advocates free and full access for the scientific community and the public at large to scientific articles and other teaching and research materials by publishing them in open access journals or uploading them onto open access institutional or thematic repositories.

Open access to scientific information can greatly benefit all players in the scientific communication system - scientists, authors, institutions, libraries, publishers, funders, and society as a whole. Avoiding a duplication of scientific efforts, which saves time and money, is one of its main advantages. In the particular case of authors and institutions, it can help them reach a much bigger audience than that provided by subscription journals - even the most prestigious and popular ones. Various surveys have revealed an increase in the visibility and impact of papers, based on the amount of citations received.[1-3]

In Cuba, the health sector was the first to adopt free software and open access to content in order to facilitate equitable and extensive access to electronic information. One of the first measures to in- crease access to this type of information was the creation of electronic versions of every Cuban medical journal. At present, the publishers Editorial de Ciencias Médicas produces 30 scientific journals, while some health institutions publish their own journals. All of them are available in electronic format and, since 1994, access to them has been free and unrestricted for the Cuban and international medical and scientific communities. The editing costs of these publications are being fully met by the Editorial de Ciencias Médicas and the Ministry of Public Health.

However, to date, Cuban medical journals have not been known or publicized as open access journals. (The term "open access journals" originated in English-speaking countries, such as the United Kingdom and the USA). Hence, the great importance of establishing to what extent Cuban researchers know and are familiar with open access journals and what their attitudes and interests are regarding publishing papers in such journals. This assessment of the present situation may be a first step toward further actions intended to favor and disseminate the Open Access Movement in Cuba and to fully exploit its potential.

\section{METHODS}

This paper summarizes some of the outcomes of a descriptive cross-sectional study conducted between March and June 2007 to explore the knowledge and attitudes of Cuban health researchers concerning the Open Access Movement in the field of scientific information. It describes only the most relevant results related to open access journals. A 20-question questionnaire was designed based on those used in previous related studies, mainly by Tenopir \& King, $[4,5]$ on the patterns of use of electronic publications, and the studies on author knowledge of and attitudes toward the Open Access Movement, by Swan \& Brown[6,7] and De Beer.[8]

Because the Open Access Movement concerns primarily scientific information, researchers working in health research institutes were considered the best group in which to carry out this first study in Cuba. Since the 1960s, these institutions, working in research, teaching, and health care within their respective specializations, have been officially defined as the highest level centers within the Ministry of Public Health.[9]

Our cohort consisted of the 530 researchers working at 11 national health institutes at the time the study was conducted. The sample, selected through stratified random sampling based on the number of researchers in each institute, included 259 researchers. A 62\% positive response was obtained from the sample (160 researchers). 
To determine knowledge of and attitudes toward open access journals, the following variables were used: information about initiatives of and terms related to the Open Access Movement; publications in open access journals; reasons to publish papers in open access journals; and reasons for refusing to publish them in open access journals. The information level variable included three categories: "I have not heard the term," "I have heard the term," and "I know what this is/does;" while the publications in open access journals variable had three categories, i.e., "Yes," "No" and "I do not know." The variables regarding reasons to publish and reasons not to publish were presented in two lists (one for each reason) of multiple-choice questions.

Answers to the questionnaires were encoded and copied into a Microsoft Excel spreadsheet. Descriptive statistics and bivariate correlation analyses were performed using the SPSS statistical software, version 10.0 for Windows.

Of the techniques pertaining to multivariate analytical methods, correspondence analysis was used. It facilitates the dimensional reduction of a class of items as per a series of attributes and the creation of a perceptive map of items having such attributes. To do that, it employs a cross tabulation of two category variables and then turns non-metric data into metric ones, performs a dimensional reduction, and creates a perceptive map.[10] In this case, the maps that were created revealed correlations between pairs of variables.

\section{RESULTS \& DISCUSSION \\ Knowledge About \& Attitudes Towards the Open Access Movement}

As an initial criterion to ascertain how familiar they were with open access journals, the participants in the study were provided with a list containing the main initiatives and terms associated with the Open Access Movement literature published on this topic. Generally, knowledge about these terms was found to be scarce. These findings, and the specifications described below, coincide with those obtained in similar studies conducted in other countries.[6-8,11-14]

As shown in Table 1, the initiatives best known to the surveyed researchers were those providing open access to biomedical journals: PubMed Central, HINARI and BioMED Central. Notably, $87 \%$ of participants did not know about the Public Library of Science (PLoS). These results indicate that in spite of constant local efforts to provide research institutes with a computing and connectivity infrastructure that enables their researchers to access all available national and international information resources through INFOMED (The Cuban Health Care and Telecommunications Network and Portal), the lack of knowledge about these initiatives may be limiting the researchers' access to scientific data which may be of interest to them.

The term "open access journal" was unknown to 55.2\% of participants. Thus, the percentage who claimed they knew, or at least had heard of, open access journals was quite low in comparison with the results from previous studies.[6,8,12,15]
The other major strategy used to provide open access - a depository for, or self-archiving of, articles and other scientific materials in institutional and thematic repositories - was also unknown to a very large number of the Cuban researchers polled in the study. Terms such as eprint, self-archiving and institutional repositories were virtually unheard of; only $8 \%, 4 \%$ and $6 \%$ of participants, respectively, replied that they knew what these were. Nevertheless, little understanding of repositories, much less open access journals, has been found in other countries as well.[7,15] In a study carried out by the German Research Society, only $26 \%$ of biomedical scientists were found to have knowledge of repositories or preprint archives.[12]

A study of biomedical science authors in Spain also found that they had little knowledge of these matters.[13] A possible explanation for this, which we believe also applies in Cuba, is that the Open Access Movement's terms and initiatives emerged in highly developed countries, such as the United Kingdom and the USA and, consequently, it is mainly authors in these countries who are aware of and familiarized with these terms - which originate from their native language. In the case of Cuba, a contributing factor already described above may have also played a role: the fact that Cuban biomedical journals have, up to now, not been promoted as open access journals; for example, there is no explicit indication in their About the Journal sections or in the authors' guides that they are open access publications.

Other terms associated with this movement were also virtually unknown to the researchers surveyed in our study. For example, nearly $80 \%$ of them had never heard about the crisis scientific journals are going through, $81 \%$ did not know about eprints, and $93 \%$ had not heard of the Creative Commons license.

Table 1: Knowledge About the Open Access Movement: Researchers Polled at Cuban Health Research Institutes, 2007

\begin{tabular}{|lccc|}
\hline & $\begin{array}{c}\text { I have not heard } \\
\text { about it (\%) }\end{array}$ & $\begin{array}{c}\text { I have heard } \\
\text { about it (\%) }\end{array}$ & $\begin{array}{c}\text { I know what } \\
\text { it is/does (\%) }\end{array}$ \\
\hline PubMed Central $\mathrm{n}=150$ & 20 & 17.3 & 62.7 \\
\hline HINARI $\mathrm{n}=147$ & 33.3 & 17.0 & 49.7 \\
\hline BioMed Central $\mathrm{n}=140$ & 29.2 & 22.9 & 47.9 \\
\hline Preprints $\mathrm{n}=141$ & 65.2 & 11.3 & 23.4 \\
\hline Open Access Journals $\mathrm{n}=145$ & 55.2 & 22.7 & 22.1 \\
\hline eprints $\mathrm{n}=141$ & 80.9 & 11.3 & 7.8 \\
\hline Institutional Repositories $\mathrm{n}=140$ & 79.3 & 14.3 & 6.4 \\
\hline Self-Archiving $\mathrm{n}=137$ & 87.6 & 8.0 & 4.4 \\
\hline PLoS $\mathrm{n}=139$ & 87 & 8.6 & 4.3 \\
\hline Crisis in Scientific Journals $\mathrm{n}=143$ & 79.7 & 16.1 & 4.2 \\
\hline BOAI $\mathrm{n}=142$ & 93.7 & 3.5 & 2.8 \\
\hline Berlin Declaration $\mathrm{n}=142$ & 85.2 & 12.0 & 2.8 \\
\hline Creative Commons $\mathrm{n}=142$ & 93.0 & 4.9 & 2.1 \\
\hline ArXiv n=141 & 94.3 & 4.3 & 1.4
\end{tabular}

Source: Poll

BOAI (Budapest Open Access Initiative): First Declaration on Open Access to Information, published on February 14, 2002; Berlin Declaration: Second Declaration on Open Access that defined the strategies for the implementation of open access; Creative Commons: A series of copyright licenses to facilitate the dissemination and use of public domain information. 


\section{Publication in an Open Access Journal}

A large number (65\%) of the Cuban health researchers surveyed in our study stated that they had not published any of their works in an open access journal in the last 3 years. Open access journals were concisely defined in our study as those offering the contents of their electronic versions free of charge. This indicates that these researchers do not identify Cuban journals as open access, perhaps because they have little knowledge of this matter or because these journals have not been classified or publicized as such. This finding might also explain the insufficient publication of scientific papers both in Cuban and in foreign journals, which is affecting the country's biomedical sector, as some Cuban authors have warned. $[16,18]$

Figure 1. Publication in Open Access Journals in the Last Three Years: Researchers Polled in Cuban Health Research Institutes, 2007

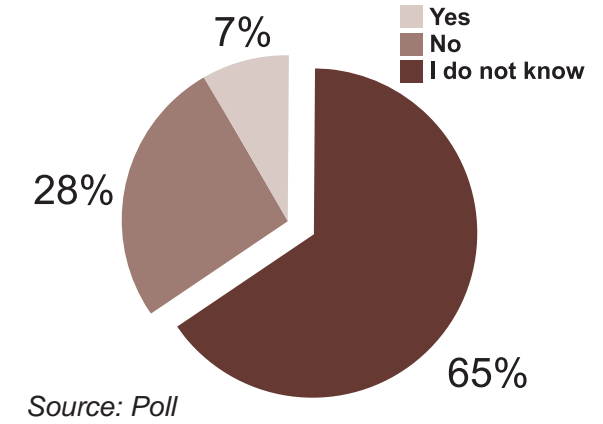

Hess et al. reported only $23 \%$ of medical researchers participating in their study had published in open access journals, the group with the lowest percentage reported so far - including those described in the German Scientific Literature and Information Systems study.[14] This study previously included a query about participants' experience consulting open access electronic resources. Sixty-two percent of medical professionals had done so, proving that accessing literature in open access journals was twice as frequent as publishing in them.[14]

Correlation between degree of knowledge of open access journals and the number of papers published in them was established. The association between variables was represented in a two-dimensional map created through correspondence analysis (Figure 2).

The black box (1), represents papers published in open access journals "Yes" variable; the gray box (3) represents the open access journals "I know what this is/does" variable. An affirmative answer to papers published in open access journals is closely associated with the answer "I know what this is/does", while a negative response coincides with the statement "I have not heard the term." This suggests that greater knowledge of open access journals implies greater inclination to publish in them.

The chief motivation to publish in open access journals, as stated by $90 \%$ of the researchers who said they have done so in the last three years, was precisely that they offer free and full access. This coincides with the reason given by participants in studies conducted in other countries,[6,19] and validates the view that information and knowledge should be socialized and shared. Other reasons given by a significant number of the participants included: open access journals' wide audience and prestige (50\% and $41 \%$, respectively), followed by perceived impact of these journals and the idea that they publish articles more quickly than print and subscription journals.

However, more than half (54.6\%) of those who said they had not sent a paper to an open access journal, pointed to an absence of knowledge about this kind of journal as the reason. And 35\% indicated they had not been able to find any open access journal to publish their work. These results reinforce the idea that it is necessary to publicize the advantages and potential of open access to information resources, and make it known that all Cuban biomedical journals offer such access.

In the study carried out by Swan \& Brown,[6] 69\% of authors said that among their reasons for not publishing their papers in these journals was their perception that open access journals had limited impact and little prestige. However, these two parameters were not highly significant $(0.7 \%)$ among the group of Cuban researchers studied and these, therefore, do not seem to be major impediments for them to adopt a more positive attitude toward publishing papers in open access journals.

At present, various arrangements are in place to provide open access to journal content. Some journals cover all publishing costs, while others have authors meet some of these expenses. The latter arrangement is used by big open access journal publishers, such as BioMed Central and the Public Library of Science (PLoS). Some studies conducted in other countries have shown that, in fact, the number of traditional journals that charge authors for publishing their works is higher than that of open access journals that do so.[6,20] However, many people have expressed concern that this author-pays policy may be locking out researchers in developing countries, research on underfunded subjects, and young authors unable to pay. Furthermore, this policy may ultimately end up discouraging publication in these journals. Although specific questions on this issue were not included in the questionnaire given to Cuban researchers, some $25 \%$ of participants indicated that pecuniary reasons had prevented them from submitting papers to open access journals. Nevertheless, it is not clear whether these answers were based on concrete experience or conjecture.

\section{CONCLUSION}

Although the health sector was the first to adopt a strategy of open access to scientific and technical information to provide all Cuban institutions with equitable access to scientific information,

Figure 2: Correlation between Knowledge about Open Access Journals and Publication in Them: Researchers Polled at Cuban Health Research Institutes, 2007

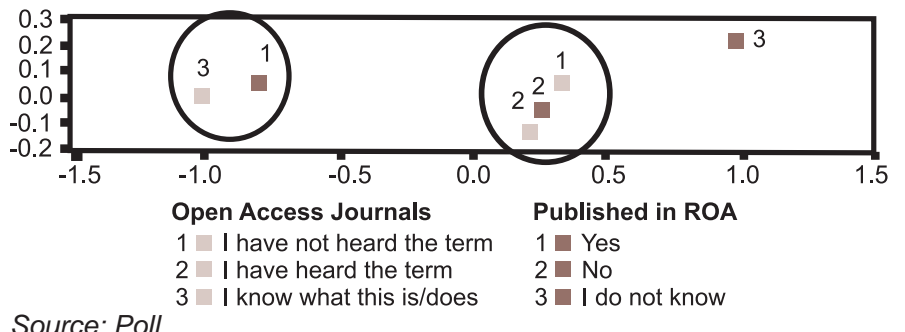


this study found scarce knowledge about the Open Access Movement's initiatives and terms. This conclusion applies not only to terms defining the movement's main strategies (publication in open access journals and self-archiving in digital repositories) but also to other scientific communication terms and concepts such as the crisis in scientific journal publication, Creative Commons licenses, or preprints and eprints.

Researchers surveyed were most familiar with initiatives providing open access to biomedical scientific journals, such as PubMed Central, HINARI, and BioMED Central, with the notable exception of the Public Library of Science (PLoS), which was unfamiliar to most of them. This lack of knowledge hinders access to articles of interest to researchers published in open access journals, repositories, or by virtue of arrangements such as those in place at PubMed and HINARI.

It is evident that, despite their availability in electronic format and full accessibility free of charge to the Cuban and international scientific communities, Cuban journals may still not be perceived by
Cuban researchers as open access journals. Perhaps it would be advisable to concurrently promote the advantages of the Open Access Movement, the open access nature of Cuban journals, and the use of Creative Commons licenses and how authors can benefit from them.

It was also found that our researchers may be using open access publications solely as readers or consumers of information, while not exploiting open access publishing opportunities for their work, thereby expanding their audience and visibility.

In the Cuban context, various actions should be taken: further research on attitudes toward and knowledge about the Open Access Movement, training authors in open access potential to further disseminate their scientific papers, socializing scientific knowledge, building institutional repositories, and implementing policies to guarantee open access through self-archiving. Moreover, involvement of scientific leaders in these strategies should be strengthened (publication in open access journals and self-archiving), which could help change the passive and conservative attitudes of other researchers. 1 -

\section{REFERENCES}

1. Eysenbach, G. (2006). Citation Advantage of Open Access Articles. PLoS Biology. 4(5).

2. Hajjem C, Harnad S, \& Gingras Y. (2005). Ten-Year Cross-Disciplinary Comparison of the Growth of Open Access and How it Increases Research Citation Impact. IEEE Data Engineering Bulletin, 28(4).

3. McVeigh, ME. (2004). Open Access Journals in the ISI Citation Databases: Analysis of Impact Factors and Citation Patterns. A citation study from Thomson Scientific [cited $2006 \mathrm{Jul}$ 2]. Available from http://www. isinet.com/media/presentrep/essayspdf/ openaccesscitations2.pdf

4. Tenopir C, King DW, Boyce P, Grayson M, Zhang Y. Ebuen M. Patterns of journal use by scientists through three evolutionary phases. D-Lib Magazine 2003; 9(5).

5. Tenopir C, King DW, Bush A. How medical faculty use print and electronic journals. J Med Library Assoc 2004; 92(2): 233-241.

6. Swan A, Brown S. Report of the JISC/OSI open access journal authors survey. Cornwall: Key perspective; 2004. [cited 2007 May 17]. Available from: www.keyperspectives.co.uk

7. Swan A, Brown S. Open access selfarchiving: An author study. Cornwall: Key perspective; 2005. [cited 2007 May 17]. Available from: www.keyperspectives. co.uk

8. De Beer J. Open Access scholarly communication in South Africa: A role for $\mathrm{Na}-$ tional Information Policy in the National System of Innovation. 2005. [cited: 2007 Apr 17]. Available from: http://eprints.rclis. org/3110/

9. Ministerio de Salud Pública de Cuba. (1966). Resolución Ministerial No. 500.
10. González López-Valcárcel, B. (1991). Análisis multivariante: Aplicación al ámbito sanitario. Barcelona: SG Editores.

11. Allen J. Interdisciplinary differences in attitudes towards deposit in institutional repositories. 2005. [cited: 2007 May 7]. Available from: http://eprints.rclis.org/ archive/00005180/01/FULLTEXT.pdf.

12. DFG. Deutsche Forschungsgemeinschaft. Publishing Strategies in Transformation? Results of a study on publishing habits and information acquisition with regard to open access. Weinheim, Germany: Wiley-VCH Verlag GmbH \& Co. KGaA; 2005.

13. Hernández-Borges AA, Cabrera-Rodríguez $\mathrm{R}$, Montesdeoca-Melián A, Martínez-Pineda B, Torres-Álvarez de Arcaya ML, Jiménez-Sosa A. Awareness and attitude of Spanish medical authors to open access publishing and the "author pays" model. J Med Library Assoc 2006; 94(4): 449-451, e218

14. Hess T, Wigand RT, Mann F, von Walter B. Open Access \& Science Publishing - Results of a Study on Researchers' Acceptance and Use of Open Access Publishing, Management Reports of the Institute of Information Systems and New Media. Munich: LMU Munich; 2007.

15. Rowlands I, Nicholas D, Huntingdon P. Scholarly communication in the digital environment: what do authors want? Findings of an international survey of author opinion: project report. London: Centre for Information Behaviour and the Evaluation of Research; 2004.

16. Ministerio de Salud Pública de Cuba. Programa para el fomento de la publicación científica en Ciencias de la Salud. 2005. [cited: 2007 May 16]. Available from: http:// intranet.sld.cu/documentacion/documen- tos/programas/programa-para-el-fomentode-la-publicacion-17-05-05.doc/

17. Rojas Ochoa F. Panorámica general de las revistas biomédicas de Cuba. Presente y futuro. Acimed 1998 [cited: 2007 May 6]; 6(1). Available from: http://www.bvs.sld.cu/ revistas/aci/vol6_1_98/aci06198.htm

18. Dorta-Contreras JA. En defensa de nuestra producción científica Acimed 2006 [cited: 2007 May 6]; 14(3). Available from: http:// www.bvs.sld.cu/revistas/aci/vol14_3_06/ aci15306.htm

19. Warlick S, Vauhhan KTL. Factors influencing publication choice: why faculty choose open access. Biomedical Digital Libraries 2007 [cited: 2007 Apr 4]; 4(1). Available from: http://www.bio-diglib.com/content/4/1/1

20. Kaufman-Wills Group. The facts about open access. The Association of Learned and Professional Society Publishers (ALPSP) research report. 2005. [cited: 2007 Jul 10]. Available from: http://www.alpsp.org/ForceDownload. asp?id=70.

\section{THE AUTHORS}

Nancy Sánchez Tarragó (Corresponding Author) Specialist in Technical-Scientific Information and Library Technologies, Coordinator, Scientific Information and Informatics Department, National Health Trends Analysis Unit, Havana Assistant Professor, Communications School, University of Havana. Contact: sanchezn@infomed.sld.cu

J. Carlos Fernández Molina, Doctor of Documentation Science, Communication and Documentation School, University of Granada, Spain.

This paper presents partial results from ongoing doctoral research. 